cio. Foi extraordinário, por exemplo, o curso em que passamos da Casa de Salomão de Francis Bacon à Voyage en Icarie de Cabet, acompanhando o ritmo da utopia, os impasses do homem e as saídas para enfrentá-los. Daí também brotavam jardins, fontes, cidades, a geometria do Paraíso, os vampiros, a science fiction, de Lovecraft a Silverberg. Dificilmente haverá em mãos tão lúcidas voz tão poética!

Lembro-me muito bem que um colega, nos corredores das "colméias", um dia falou:

- Que bom que vamos agora ouvir Ruy Coelho, o professor que mais ama literatura, enquanto outros tantos parecem mesmo odiá-la...

O fluxo de sua fala percorria os espaços e, de repente, pensávamos que as pessoas até podiam desaparecer, virar fantasmas ou bonecos mas, de fato, ao contrário, ele precisava delas, muito mais do que se podia crer, buscava sua ajuda para encontrar o elo na cadeia perdida, para com ele dar contas do "Benito Sereno" de Melville.

Disputava-se também, por isso, o prazer de levá-lo em casa, de enfrentar o trânsito em sua companhia. Tanto Teófilo Queiroz, seu amigo, como eu nos alternávamos nesta tarefa-glória. O carro, caixa de ressonância, fazia com que a cidade lá fora nem existisse. Era tempo de escuta que trazia algo de invenção, o comentário agudo que nos deixava aturdidos e fascinados.

\section{OS “ATRAPALHOS”}

Numa defesa de tese, das inúmeras de que participou, trazendo sempre o comentário instigante, dando o incentivo, o aplauso ou a compreensão das falhas, ao desfazer toda a tese de um candidato que argüía, perdido entre as páginas que se tinham descolado, embaralhado, dirige-se à platéia e comenta:

- Até que enfim consegui me encontrar. Risos das pessoas e a quebra do tom grave e enfatuado trazido por aquele ambiente solene. Assim, também o trocar de reuniões (tormento da vida universitária), o equívoco e o esquecimento de qual era mesmo aquela em que devia estar: "Pelas caras presentes é que recupero a reunião".

Aquela tarde de abril em São Paulo estava mais luminosa do que as outras. Uma luz de Lisboa na primavera. Alguns amigos e poucos colegas se encontrando na "Consolação" para a despedida de Ruy Coelho.

Chega então uma amiga e nos conta da última visita que ela lhe fizera: ele já desfigurado, sem forças e, de repente, perguntaram-lhe sobre os últimos acontecimentos do país, sobre os impactos do plano econômico aturdidor. Eis que retoma aquela força e nele se instala toda a velha magia. As mãos recomeçam o bailado, os olhos brilham, o discurso flui: - Estou aqui tentando discernir os limites da catástrofe. Estava lançado o mote.
- As citaços entre aspas correspondem a trechos de aulas de R. C.

\title{
Excertos
}

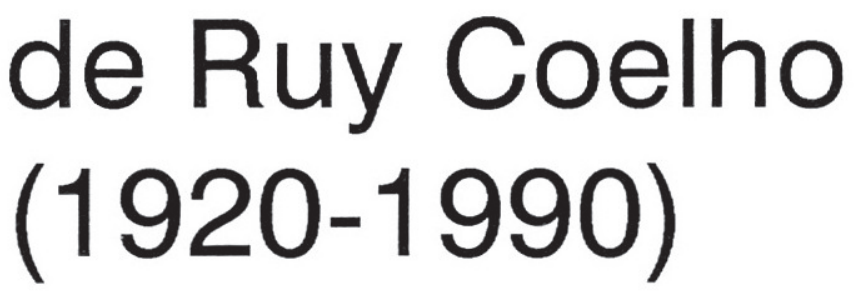

Apresentação de DECIO DE ALMEIDA PRADO

Como exemplo das preocupaçôes e do estilo de Ruy Coelho transcrevemos a seguir algumas páginas, entre as muitas que escreveu. $O$ primeiro trecho, extratdo do ensaio "Marcel Proust e a nossa época", saiu na revista Clima, no 1, maio de 1941. Era a sua estréia em letra de forma, aos vinte anos de idade. $O$ segundo trecho reproduz a parte introdutória do seu
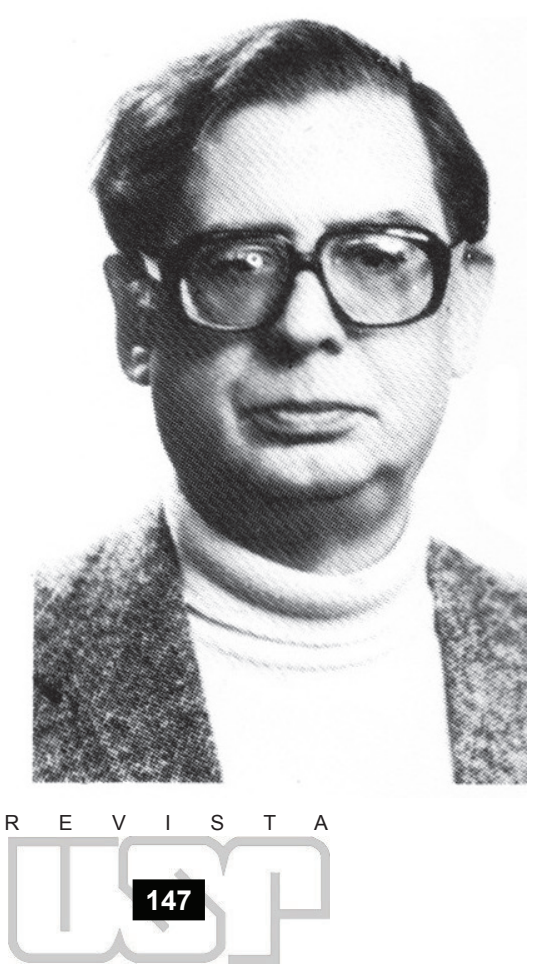
último artigo, "Planos da cognição e processos culturais", publicado na revista Tempo Social, da USP, no 1, 10 semestre de 1989.

São fragmentos apenas, pequenos pedaços de um todo muito maior. Mas servem para lembrar a seus amigos as duas áreas do pensamento em que ele atuou, a artistica e a cientffica, a da literatura e a da antropologia. Diversas enquanto natureza e métodos, convergiam em seu espirito na medida em que compartilhavam a mesma esquiva materia - o ser humano.

\section{Marcel Proust e a nossa época}

Já em 1922 Paul Souday escrevia que comparar Proust a Saint-Simon e Montaigne era um lugar comum. Hoje a chapa favorita é lançada por Crémieux, que encontramos no sr. Jorge de Lima, numa fórmula simplória - "Proust é Wagner direitinho". Evocamse ainda Balzac e Stendhal; em pintura apela-se para o impressionismo. Eu mesmo, para escrever estas linhas, em notas esparsas, estendera-me longamente comparando La recherche du temps perdu com uma catedral barroca - a mesma harmonia de conjunto, a mesma superabundância de ornatos e minúcias atingindo o equilíbrio no extremo limite do caos, o ilusionismo, o agencement, o arranjo calculado de todas as partes, até os mínimos pormenores, em vista do todo...

Quando compus a versão definitiva nada disso me satisfez.

Sem dúvida, certas descrições de festas, a obsessão da nobreza, a atenção voltada para os atos pequeninos e significativos que explicam em grande parte as personalidades, outros tantos traços que os comentaristas não se cansam de salientar, o aparentam a Saint-Simon. Mas o espírito que anima Proust é muito diferente. Para o fidalgo do século XVIII a Corte era o centro vital e intelectual do país. Através da frivolidade dos salões, da aparente gratuidade dos atos dos grandes senhores, de todos os que se aproximavam do rei, parecendo unicamente ocupados de questões de hierarquia nobiliárquica ou com os próprios prazeres, debatiam-se os interesses primordiais da nação francesa. Decidia-se, não só daquilo que dizia respeito à política, como operações militares e fatos relativos à vida do espírito.

A discussão, hoje mesquinha, de preeminência de colocação de carruagem, tinha importância, pois era índice do poder que cada qual possura. Enfim, um organismo ainda vigoroso e em pleno funcionamento eis o que deixou retratada sua espantosa observação.

Bem diferente se apresentava a sociedade para o dandy do século XIX. Subsistem os órgãos, mas desaparecem as funções. A atmosfera é de irritante esnobismo, de agitação estéril de parasitas, cujo centro de interesse na vida é ser admitido em dados salões ou excluir de seu próprio todos os que não tinham títulos retumbantes (de fidalguia ou quaisquer). A impressão que se tem é semelhante à dos presépios mecânicos, popularíssimos na Rússia, e que tanto inspiraram os ballets. Ao som da caixinha de música desenrola-se o cortejo dos personagens com suas mesuras e movimentos vários. Cessa a música - por um momento eles desfilam parados. Nesta suspensão do tempo, pode-se então observá-los bem em seus traços marcantes. Depois o mecanismo faz ouvir nova ária que os põe de novo em movimento.

Da pouca leitura que tive de Montaigne colhi impressão bem diversa da de Proust. A similitude indicada por Pierre Abraham, da inquietação de espírito (atribuída à ascendência judaica - a mãe de Montaigne, Lopez, e a mãe de Proust, Weil), de pensée qui s'essaye, não me parece tão flagrante. Há de fato "ensaio" em Montaigne, esforço explorador do espírito, que tateia todos os terrenos e se lança em todas as direções, com a formidável curiosidade do humanista da Renascença. Proust cada vez mais se isola do exterior para focalizar o próprio eu. Ambos se aparentam pela grande riqueza de vida interior. Há uma frase de Montaigne que Proust também poderia assinar: Les autres vivent en dehors; moi, je me roule en moimême. Mas no primeiro, o sentido desta vida é centrífugo, e no segundo centrípeto.

Tristão de Ataŕde faz ressaltar o parentesco com Maine de Biran. Outros com Amiel. Creio que em tudo isso há muita vontade de fazer paralelo literário. É bem diverso de Proust o calvinista Amiel, cuja obra tem como eixo o problema moral, embora em ambos, afora o diálogo interior, haja aquele traço que Marcel apontava em Mme. de Se-

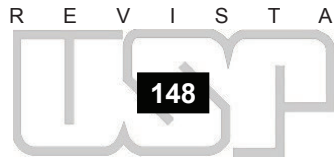


vigné ( $A$ l'ombre des jeunes filles en fleurs), ou seja, a descrição da paisagem segundo a ordem de impressões e não ordem lógica.

Quanto a Maine de Biran, um estudioso como o sr. Tristão de Ataŕde pode encontrar muitos textos coincidentes. Com um pouco mais de esforço, todos os místicos, todos os que cultivaram a vida interior poderiam ser chamados à comparação.

Os aspectos balzaquianos se fazem bem notar, embora não se prendam à essência da obra, ao contrário. É na medida em que Proust se apega ao exterior, que liga intrigas complexas, que faz agir paixões dominantes (sobretudo o amor e o esnobismo) que lembra Balzac. Sodome et Gommorrhe - II é a parte mais próxima da comédia humana.

As analogias encontradas com Wagner e os impressionistas, ao meu ver, são também superficiais. Os temas condutores em La recherche du temps perdu surgem com suavidade e desaparecem sem os entrechoques e lutas da ópera wagneriana. Não há um tema que prevaleça esmagando os outros no final, como o de Destruição de Walhala na tetralogia. Em Le temps retrouvé todos os temas se fundem lembrando mais o final de sinfonia cíclica, a que Crémieux também compara, com maior felicidade. Quem mais me evoca Proust, em música, é Débussy.

Os pontos de referência com arquitetura e pintura não devem também ser tomados em conta, não por falsos, mas por pouco profundos. Todas estas comparações são explicáveis em vista do esforço de compreendê-lo. Ante a novidade poderosa da obra, os espíritos desnorteados procuram em autores anteriores aspectos semelhantes, o repouso do já visto. Atualmente louvamos esse trabalho que permite salientar a grande originalidade da obra que estudamos.

Na realidade Proust é essencialmente literário. Como o Jean Christophe de Romain Rolland, músico-nato que todas as impressões procurava traduzir musicalmente, assim ele, desde o instante em que os campanários de Martinville se lhe estamparam na retina, sentiu um obscuro apelo que o levava a buscar, com ânsia, a expressão das misteriosas revelaçōes da arte, na palavra. A palavra foi o seu verdadeiro material, com o qual trabalhou com verdadeiro amor, com o entusiasmo fanático de um pintor da Renascença. Em carta a Gaston Gallimard, em 1919: Cher ami et éditeur vous paraissiez me reprocher mon système de retouches. Mais quand vous m'avez demandé de quitter Grasset pour venir chez vous, vous le connaissiez, car vous êtes venu avec Copeau qui devant les épreuves remaniées de Grasset s'est écrié: - Mais c'est un nouveaus livre! Conseguiu com ela traduzir sentimentos que já quase atingiam o ultravioleta ou infravermelho do espectro afetivo.

$\mathrm{O}$ estilo, um dos mais originais de toda a língua, plasma-se às necessidades de expressão as mais variadas sem nada perder do seu cunho único (para dar idéia dele sou obrigado a usar de imagens que não me satisfazem). Se descreve a igreja de Balbec, as frases se ordenam, segundo certo equilíbrio de massas. Para nos sugerir um quadro de Elstir, tritura, pulveriza os vocábulos, espalhando-os em grandes manchas irisadas como as de asas de borboleta. Na sonata ou septeto de Vinteuil, torna-se misterioso, evocativo, espalha-se em lagos de melodia. Quando tomado de verdadeira ânsia de autodefinição, procura surpreender em flagrante o mistério da vida psíquica, liga-se em associações que se prolongam em períodos de páginas, cruzando-se e recruzando-se como sistema fluvial subterrâneo, repontando aqui ou além.

Não nos iludamos, no entanto, com essas metáforas. É exatamente por ser um puro escritor que ele não tem medo de tentar a exploração de manifestações diversas de arte. Apesar de todos os aspectos que empresta às outras artes, é literatura pura, no sentido da beleza resultar do esforço de penetração da inteligência, de interpretação em termos inteligiveis das realidades que a sensibilidade atinge.

\section{Planos da cognição e processos culturais}

A antropologia cognitiva objetiva lançar luzes sobre os dinamismos coletivos do conhecimento humano. Distingue-se da epistemologia por não montar seu discurso sobre as posições a priori; como ciência empírica, investiga as formas concretas de contato do espírito humano com a realidade que se manifestam nas diferentes culturas. Desde que a 
cultura foi caracterizada como sistema simbólico, a análise deste cobre necessariamente todos os aspectos da elaboração mental coletiva, inclusive o conhecimento. Toda a obra de Lévy-Bruhl tem por foco as modalidades de conhecimento nas sociedades primitivas. Frazer concebeu a magia como forma primitiva do saber. Durkheim e Mauss deram as bases científicas para a investigação das classificações primitivas, que se prolonga até a atualidade. Há razões, portanto, para sustentar que a antropologia cognitiva não é um domínio especial da ciência antropológica, mas constitui seu todo. Contrariamente, para alguns a antropologia cognitiva nasceu em meados da década de 50, com os trabalhos de Frake, Conklin e outros, surgindo como revolução radical na ciência do homem.

No meu entender, tal revolução não se deu, ou, pelo menos, não constituiu transformação radical de paradigmas, consoante os moldes que T. S. Khun propôs para análise das revoluções científicas. O que de fato aconteceu foi uma mudança paulatina de ênfase, métodos e definição de objeto. O sistema sócio-cultural, para Durkheim e RadcliffeBrown, como para o Lévi-Strauss da primeira fase, é uma ordenação de regras de conduta, quer inconsciente, quer explicitadas em códigos éticos e juŕ́dicos. Na concepção do movimento "cultura e personalidade", a cultura é a sistematização de caraterísticas psicologicas, que se tornam comuns pela unidade de processos de socialização vigentes em determinada sociedade. A antropologia do simbólico, que também se denomina antropologia semântica ou cognitiva, pôs em relevo os dinamismos da cognição, tidos por cerne da cultura.

Nas últimas décadas, os problemas do conhecimento se tornaram a preocupação primordial de investigadores nos campos da psicologia experimental, psicologia social, neuropsicologia, inteligência artificial, sociologia da ciência, e outros mais. A antropologia, preparada pelo pensamento dos pioneiros acima mencionados, abriu-se às influências de outras ciências da cognição e foi levada a refletir sobre suas próprias rá́zes. Daí resultou um grande fomento das investigações nesse terreno, de natureza vária e com diferentes enfoques. A avaliação do que se fez até agora revela considerável riqueza de idéias e dados novos, mas ao mesmo tempo produz a impressão de alguma confusão. Os segmentos da realidade recortados pela investigação raras vezes coincidem, a terminologia não é sistemática e freqüentemente recorre a neologismos; há grande ecletismo nos métodos empregados.

Este artigo é um primeiro esboço, provisório, sumário e cheio de lacunas, de ordenação de alguns conceitos da antropologia cognitiva. Parte do pressuposto que existem várias formas do conhecimento, sistematizadas em graus diversos pela cultura. Para tal ordenação, utilizo-me do conceito de planos do conhecimento cujo entrosamento e hierarquização são problemáticos, como se exporá à guisa de conclusão. Servirá para o leitor como guia comentado de uma bibliografia que, por extensa que pareça, cobre uma pequena parcela das publicações nesse campo; além do mais, é pessoal e arbitrária.

\section{Planos DA CogniçÃo}

A primeira noção que tive de planos da cognição foi-me dada por Herskovits nos seus cursos na Universidade de Northwestern. Esse autor cunhou a expressão "foco cultural", que denota a área do saber coletivo em que as noções são mais nítidas, têm maior articulação e alimentam maior número de discussões. Cada cultura elabora um foco cultural específico: na África ocidental, é a religião, sobretudo em seus aspectos rituais; nos povos africanos da zona do gado, como os Nuer e os Dinka, as atividades do pastoreio; na Grécia, a arte. Embora a divisão não seja explicitamente proposta, constituem-se dois planos, um em que o conhecimento é elaborado, e outro em que as noções são esbatidas e em que dominam as práticas.

A proposta de Herskovits ainda hoje é válida, mas a divisão, por demasiadamente ampla, não dá conta da complexidade dos fenômenos da cognição. Atenho-me a um esquema que compreende os seguintes planos: de representação perceptual, da linguagem, das práticas, dos símbolos, das categorias, das formas superiores do saber. 